\title{
Microbial Profile and Antimicrobial Susceptibility Pattern of Uropathogens Isolated From Catheter Associated Urinary Tract Infection (CAUTI)
}

\author{
Deepa Bhani*, Rekha Bachhiwal, Rajni Sharma and Rakesh Kumar Maheshwari \\ Department of Microbiology, SMS Medical College, Jaipur, Rajasthan, India \\ *Corresponding author
}

\section{A B S T R A C T}

Urinary tract infections are the most commonly acquired bacterial infections accounting for an estimated $25-40 \%$ of the nosocomial infections. Catheterization is a potential

\section{Keywords}

Catheter

associated urinary

tract infection

(CAUTI), Urinary

Tract Infections

(UTIs), Device

Associated Infection (DAI).

Article Info

Accepted:

21 June 2017

Available Online:

10 August 2017 predisposing factor of CAUTI. Study was carried out over a period of one year included 100 urine samples obtained from catheterized patients. The urine samples obtained were immediately processed in microbiology laboratory by semi-quantitative method as per standard protocol. Following isolation and identification, all the isolates were subjected to antimicrobial susceptibility testing for commonly used antimicrobial drugs. Out of 230 urine samples from catheterised patients $43.5 \%$ of cases developed catheter associated urinary tract infection (CAUTI). The most common organism causing CAUTI was found to be E. coli in $27.2 \%$ of cases, followed by Pseudomonas (20\%), Klebsiella (15.4\%), Enterobacter aerogenes (9\%), Enterobacter cloacae (0.09\%), Proteus spp. (2.7\%) and Citrobacter spp. (2.7\%). Gram positive cocci accounted only in $10 \%$ of CAUTI cases and Candida spp. in $11.8 \%$ of cases. Antimicrobial susceptibility testing revealed Imipenem $(66.7 \%-94.1 \%)$ and nitrofurantoin $(73.3 \%-88.2 \%)$ to be the most sensitive antimicrobials for frequently isolated Gram negative bacteria like E. coli and Klebsiella spp. Pseudomonades isolated were sensitive to imipenem and gentamicin (31.8\% each). Gram positive cocci were completely sensitive to linazolid and vancomycin. This study reported a high rate of CAUTI (43.5\%) and resistance to commonly used antimicrobials among CAUTI isolates, hence it is necessary to reduce urinary infection in catheterized patients by limiting the use of catheter only for proper indications and remove catheters promptly when no longer required.

\section{Introduction}

Urinary Tract Infection constitutes a serious health problem that affect millions of people each year ${ }^{1}$.

Urinary Tract Infections (UTIs) are defined as diseases which are caused by a microbial invasion of the genitourinary tract that extends from the renal cortex of the kidney to the urethral meatus ${ }^{2}$. Among UTIs acquired in the hospital, approximately $75 \%$ are associated with a urinary catheter ${ }^{3}$.
Catheter associated urinary tract infection (CAUTI) is one of the most important Device associated infection (DAI) and it is one of the leading causes of morbidity and mortality in hospitalized patients ${ }^{4}$. The risk of acquiring catheter associated urinary tract infection (UTI) depends on method and duration of catheterization, the quality of catheter care and host susceptibility 5,6,7. Host factors including female sex, prolonged catheterization, severe underlying illness, 
disconnection of the catheter and drainage tube, other types of faulty catheter care, and lack of systemic antimicrobial appear to increase the risk of catheter associated urinary tract infection (CAUTI) ${ }^{8,9}$. The incidence of CAUTI rises from 0.5 to $1 \%$ for a single "inand-out" catheterization to 10 to $30 \%$ for catheters in place for up to 4 days and up to $95 \%$ for catheters in place for 30 days or more $^{10}$.

CAUTI if left untreated, it can lead to complications such as cystitis, pyelonephritis, Gram negative bacteremia, prostatitis, epididymitis, endocarditis, vertebral osteomyelitis, septic arthritis, endophthalmitis and meningitis ${ }^{11}$. Additionally CAUTIs also result in prolonged hospital stay, increased cost and mortality ${ }^{12}$.

Present study was undertaken to find out rate of CAUTI, organisms causing it and their antimicrobial susceptibility pattern.

\section{Materials and Methods}

The present study was conducted in the Department of Microbiology, SMS Medical College and Attached Hospitals, Jaipur (Rajasthan).

A total of 230 urine samples collected from catheterised patients were included in the study. The diagnosis of CAUTI was done as per the CDC guidelines. ${ }^{3}$

\section{Inclusion criteria}

Patients from urology and surgery ward/ICU, catheterized for $\geq 48 \mathrm{hr}$ with baseline

Urine culture sterile.

\section{Exclusion criteria}

Patients with prior symptoms of UTI.

Patients catheterized for $<48 \mathrm{hr}$.
Urine samples were collected aseptically using a sterile needle and syringe from the distal edge of catheter tube into a sterile universal container and transported to the microbiology laboratory for analysis with minimum delay. The samples were processed as per routine standard laboratory procedure. This included microscopy, culture, and antimicrobial susceptibility testing.

Urine samples were inoculated with an inoculating loop of internal diameter of $2 \mathrm{~mm}$ delivering $0.001 \mathrm{ml}$ of urine for semi quantitative analysis on blood agar and MacConkey agar. Culture plates were evaluated after 18-24 hours of aerobic incubation at $37^{\circ} \mathrm{C}^{14}$.

Isolates were identified on the basis of Colony morphology, Gram staining and Biochemical reactions ${ }^{15,16,17}$. Urine samples with no more than two species of organisms, at least one of which is a bacteria of $\geq 10^{5} \mathrm{CFU} / \mathrm{ml}$ were taken into consideration. ${ }^{3}$

Antimicrobial susceptibility testing of isolated organism was performed by Kirby Bauer disk diffusion method ${ }^{18}$.

\section{Results and Discussion}

Out of 230 catheterised patients under study, $100(43.5 \%)$ cases developed CAUTI.

A total of 110 uropathogens were isolated from the 100 urine samples from CAUTI cases. Of the 100 samples, single isolate was obtained in 90 samples and in the remaining 10 samples more than 1 isolate (i.e. 2 isolates) were obtained.

Among the 110 uropathogens Gram negative bacilli showed predominance.

E. coli $(27.2 \%)$ were the most frequently isolated pathogens followed by Pseudomonas 
(20\%) and Klebsiella spp (15.4\%). Other GNB accounted for $0.09 \%-9 \%$ of cases (Table 1).

Among the Gram positive pathogens isolated, Enterococcus spp (6.3\%) was the commonest pathogen isolated followed by Coagulase positive Staphylococci and Coagulase negative Staphylococci (1.8\% each). Candida spp accounted for $11.8 \%$ cases (Table 1).

Among the commonly used antimicrobials, imipenem and nitrofurantoin were the most sensitive antimicrobials to E. coli $(66.7 \%$ and $73.3 \%)$ and Kebsiella spp $(94.1 \%$, and $88.2 \%$ ). Sensitivity to other commonly used antimicrobials including Aminoglycosides, fluoroquinolones, $3^{\text {rd }}$ and $4^{\text {th }}$ generation cephalosporins were found to be lower than imipenem and nitrofurantoin. Ampicillin showed complete resistance to Escherichia coli, Klebsiella spp, Enterobacter cloacae, Proteus spp and Citrobacter (Table 2).

Table 3 shows antimicrobial sensitivity pattern of Pseudomonas spp. Pseudomonas isolated were most sensitive to imipenem and gentamicin $(31.8 \%$ each) followed by Aztreonam and Piperacillin + Tazobactam (18.2\% each) and were completely resistant to levofloxacin.

Antimicrobial sensitivity pattern of Enterococcus and Staphylococci spp revealed that both of these uropathogens were completely sensitive to vancomycin and linezolid. Sensitivity of Enterococcus spp for nitrofurantoin, penicillin and norfloxacin were found to be $57.6 \%, 42.8 \%$ and $28.6 \%$ respectively.

Sensitivity of Staphylococci for doxycyline, gentamicin was $75 \%$ each while levofloxacin and nitrofurantoin showed sensitivity of $50 \%$ each. Staphylococci were least sensitive to norfloxacin, erythromycin and cefoxitin $(25 \%$ each) (Table 4).

Catheter associated urinary tract infections are the most common nosocomial infections, $75 \%$ cases of UTI in catheterised patients is due to use of urinary catheter ${ }^{3}$. A urinary catheter provides bacteria, a portal of entry into the urinary tract. Bacteria may ascend into the tract via the external or internal surface of the catheter $^{11}$. Also urinary catheter use is often associated with catheter-related biofilms ${ }^{19}$.

In the present study rate of CAUTI in catheterized patients was found to be $43.5 \%$. Chaudhari et al., ${ }^{21}$ reported $44 \%$ and Poudel et al., ${ }^{22}$ reported $55 \%$ rate of CAUTI in their study which is in agreement with the present study. However studies conducted by Chatterjee et al., ${ }^{23}$ and Dimri et al., ${ }^{24}$ reported a higher rate of CAUTI $(86.6 \%$ and $86.1 \%$ respectively). A lower rate of CAUTI has been reported by Bhatia et al., ${ }^{25}(28.8 \%)$, Prajapati et al., ${ }^{26}(13.14 \%)$ and Roel et al., ${ }^{27}$ $(15.5 \%)$.

The source of microorganisms causing CAUTI can be endogenous typically via meatal, rectal, or vaginal colonization or exogenous, such as via equipment or contaminated hands of healthcare personnel ${ }^{11}$.

In the present study Gram negative bacteria $(78.18 \%)$ were predominantly isolated from CAUTI cases. Gram positive bacteria accounted for only $10 \%$ of cases. Candida spp constituted $11.8 \%$ of uropathogens isolated.

Amongst the GNB, E. coli was found to be the most common uropathogen (27.2\%), followed by Pseudomonas spp. (20\%), Klebsiella spp. (15.4\%), Enterobacter aerogenes (9\%), Enterobacter cloacae (0.09\%), Proteus spp. (2.7\%) and Citrobacter spp. (2.7\%). 
Int.J.Curr.Microbiol.App.Sci (2017) 6(8): 2446-2453

Table.1 Uropathogens isolated from CAUTI cases

\begin{tabular}{|l|l|l|}
\hline Organisms & Number & Percentage\% \\
\hline Escherichia coli & 30 & $27.2 \%$ \\
\hline Pseudomonas spp & 22 & $20 \%$ \\
\hline Klebsiella spp & 17 & $15.4 \%$ \\
\hline Enterobacter aerogenes & 10 & $9 \%$ \\
\hline Enterobacter cloacae & 1 & $0.09 \%$ \\
\hline Proteus spp & 3 & $2.7 \%$ \\
\hline Citrobacter spp & 3 & $2.7 \%$ \\
\hline Enterococcus spp & 7 & $6.3 \%$ \\
\hline CONS & 2 & $1.8 \%$ \\
\hline CPS & 2 & $1.8 \%$ \\
\hline Candida spp & 13 & $11.8 \%$ \\
\hline
\end{tabular}

Table.2 Antimicrobial sensitivity pattern of isolated Gram negative bacteria

\begin{tabular}{|l|l|l|l|l|l|l|l|l|l|l|l|l|}
\hline & & & & & & & & \\
\end{tabular}

Table.3 Antimicrobial sensitivity pattern of Pseudomonas spp (N=22)

\begin{tabular}{|l|l|l|}
\hline Antibmicrobial Drug & No (22) & $\%$ \\
\hline Piperacillin + Tazobactam & 4 & 18.2 \\
\hline Ceftazidime & 2 & 9 \\
\hline Cefepime & 3 & 13.6 \\
\hline Aztreonam & 4 & 18.2 \\
\hline Imipenem & 7 & 31.8 \\
\hline Amikacin & 2 & 9 \\
\hline Gentamicin & 7 & 31.8 \\
\hline Levofloxacin & 0 & 0 \\
\hline Norfloxacin & 5 & 22.7 \\
\hline
\end{tabular}


Table.4 Antimicrobial sensitivity pattern of Staphylococcus spp. $(\mathrm{N}=4, \mathrm{CONS}=2$ and $\mathrm{CPS}=2)$ and Enterococcus $\operatorname{spp}(\mathrm{N}=7)$

\begin{tabular}{|l|l|l|}
\hline Antimicrobial drug & Staphylococci $\mathrm{N}=4$ & Enterococci $\mathrm{N}=7$ \\
\hline Cefoxitin & $1(25 \%)$ & -- \\
\hline Doxycycline & $3(75 \%)$ & -- \\
\hline Gentamicin & $3(75 \%)$ & -- \\
\hline Erythromycin & $1(25 \%)$ & -- \\
\hline Vancomycin & $4(100 \%)$ & $7(100 \%)$ \\
\hline Linezolid & $4(100 \%)$ & $7(100 \%)$ \\
\hline Nitrofurantoin & $2(50 \%)$ & $4(57.2 \%)$ \\
\hline Levofloxacin & $2(50 \%)$ & -- \\
\hline Norfloxacin & $1(25 \%)$ & $2(28.6 \%)$ \\
\hline Penicillin & - & $3(42.8 \%)$ \\
\hline
\end{tabular}

Poudel et al., ${ }^{22}$ also reported E. coli as predominant isolate $(40.7 \%)$, followed by Pseudomonas spp (11.1\%) and Klebsiella spp $(11.1 \%)$ in their study.

E. coli is the most common organism reported from CAUTI cases, the source of these strains of $E$. coli is frequently the patient's own intestinal flora ${ }^{22}$, Virulence factors of uropathogenic E. coli (UPEC) include the ability to adhere to uroepithelial cells and certain specific serotypes $\mathrm{O}$ and $\mathrm{K}$ antigens that are resistant to phagocytosis and bactericidal action of normal serum ${ }^{29}$.

In the present study Escherichia coli was isolated in $27.2 \%$ of CAUTI cases. Similar results have been reported in studies performed by Chaudhari et al., ${ }^{21}$, and Roel et al., ${ }^{27}$, with rate of isolation to be $21 \%$ and $27.2 \%$ respectively. However Poudel et al., ${ }^{22}$ have reported a higher isolation rate of $E$. coli (40.7\%).

Antimicrobial sensitivity pattern of isolates showed that imipenem (60-100\%) and nitrofurantoin $(73.2 \%-88.2 \%)$ were the most sensitive antimicrobial agents among GNB. Other antimicrobials including ceftazidime, cefotaxime, cefepime, gentamicin, amikacin levofloxacin and doxycycline showed moderate to low sensitivity. Ampicillin was found to be least sensitive (Table 2).
Sensitivity of imipenem to Escherichia coli was $66.7 \%$, for Klebsiella spp $94.1 \%$ and $100 \%$ each for Enterobacter cloacae, Proteus spp and Citrobacter spp. Nitrofurantoin showed $73.3 \%$ sensitivity for Escherichia coli, $88.2 \%$ for Klebsiella spp and $80 \%$ for Enterobacter aerogenes.

Poudel et al., ${ }^{22}$, Dimri et al., ${ }^{24}$, Manish et $a l .,{ }^{30}$, Roel et al., ${ }^{27}$ also reported imipenem as the most effective antibiotic among GNB (91$100 \%)$

Pseudomonas spp was found to be the second most frequently isolated microorganism in the present study after E. coli accounting for $20 \%$ (22/110) of all uropathogens isolated. These finding are broadly in agreement with the finding of Chaudhari et al., ${ }^{21}$ and Roel et al., 27 , who reported the isolation rate to be $21 \%$, and $18.2 \%$ respectively. A little higher rate was reported by Chatterjee et al., ${ }^{23}$ (30.67\%). While lower rate of isolation was reported by Manish et al., ${ }^{30}$, Dimri et al., ${ }^{24}$ (10.8\%).

Pseudomonas causes catheter-associated urinary tract infections through biofilm formation on the surface of indwelling catheters.

Pseudomonas isolated were maximally sensitive to imipenam and gentamicin $(31.8 \%$ each) followed by norfloxacin (22.7\%), 
aztreonam (18.2\%) and piperacillin + tazobactam (18.2\%). These demonstrated a low sensitivity to cefepime (10.6\%), amikacin $(9 \%)$, ceftazidime $(9 \%)$ and levofloxacin (0\%). Sensitivity to Gentamicin $(31.8 \%)$ to pseudomonas in the present study is broadly in agreement with that reported by Dimri et al., ${ }^{24}(30 \%)$ and Chatterjee S. et al., ${ }^{23}$ (30.44\%), while sensitivity to imipenem was lower than the other studies. Sensitivity to Aztreonam (18.2\%) correlates well with that reported by Dimri et al., (20\%). ${ }^{24}$

Among the GPC, Enterococci accounted for $6.3 \%$ cases and Coagulase positive Staphylococcus and Coagulase negative Staphylococcus (CONS) each for $1.8 \%$ cases. These were completely sensitive to vancomycin and linezolid.

CA-UTI is an important device-associated health care acquired infection. In the present study the rate of CAUTI was found to be $43.5 \%$ and most of the isolates were GNB $78.18 \%$, Escherichia coli being the predominant isolate. Most of organisms isolated were found to be resistant to commonly used antimicrobials.

Considering such a high rate of CAUTI and increasing resistance among CAUTI isolates, it is necessary to reduce urinary infection in catheterized patients by limiting the use of catheter only for proper indications and remove catheters promptly when no longer required. Infection control programs must develop, implement, and monitor policies and practices to minimize infections associated with use of these devices.

\section{Acknowledgements}

The authors acknowledge all the Faculty and technical staff of the Dept. of Microbiology \& Immunology, SMS Medical College, Jaipur for the facilities and support provided.

\section{References}

1. Hancock V, Dahl $\mathrm{M}$, and Klemm P. Abolition of biofilm formation in urinary tract Escherichia coli and Klebsiella isolates by metal interference through competition for Fur. Applied and environmental microbiology 2010; vol.76; issue 12: 3836-3841.

2. Bagshaw SM, Laupland KB. The epidemiology of the intensive care unit acquired urinary tract infections. Curr Opin Infect Dis 2006; vol.19: 67-71.

3. Centers for Disease Control. Healthcare Infection Control Practices Advisory Committee HICPAC. Guideline for prevention of Catheter Associated Urinary Tract Infectins 2009.

4. Dogru A, Sargin F, Celtic M, Sagiroglu A E, Goksel M M, Sayhan H. The rate of Device-Associated nosocomial Infections in a medical surgical intensive care unit of a training and research hospital in Turkey: one year outcomes. Jpn. J. of Infect. Dis. 2010; vol.63:95-98.

5. Brumfitt W, Davies BL, Rosser E. The urethral catheter as a cause of urinary tract infection in pregnancy and perpuerium. Lancet. 1961; vol.2: 10591061.

6. Kunin CM. Detection, prevention and management of urinary tract infections. 4th ed. Lea and Fbiger, Philadelphia, 1987; 245-298.

7. Laupland K B, Zygun D, Davies H, Church D, Louie T, Doig C. Iincidence and risk factors for acquiring nosocomial urinary tract infection in the critically ill. J Crit Care 2002; vol.17: 50-57.

8. Stamm WE. Catheter-associated urinary tract infections: epidemiology, pathogenesis, and prevention. American J of Med, 1991; vol.91 (3b) 65s-71s. 
9. Walter ES. Urinary tract infections and pyelonephritis. Harrison's principles of internal medicine. 16th edition 2004; vol.II; 1715-21.

10. Dickson $\mathrm{G} M$ and Bisno $A$. Infections associated with indwelling devices: infections related to extravascular devices antimicrobial agents and chemotherapy. American Society for Microbiology 1989; vol. 33(5): 602607.

11. Centers for Disease Control. 2012. Device- associated module: Catheter associated urinary tract infection event. http://www.cdc.gov/nhsn/pdfs/pscmanu al/7psccauticurrent.pdf

12. Klevens RM, Edwards JR, Richards CL, Horan TC, Gaynes RP, Pollock DA et al., Estimating health care-associated infections and deaths in U.S. hospitals, 2002. Public Health Rep 2007; 122:1606.

13. Bailey and Scott's. Infections of the urinary tract. Textbook of Diagnostic Microbiology. 13th edition; 919-924.

14. Bailey and Scott's. Traditional Cultivation and Identification. Textbook of Diagnostic Microbiology. 13th edition; 81-93.

15. Collee JG, Marr W. Culture of bacteria. In: Collee JG, Fraser AG, Marmion BP, Simmons A, editor. Mackie and McCartney Practical Medical Microbiology. 14th edition New York: Churchill Livingstone 1996; 113-130.

16. Collee JG, Miles RS, Watt B. Staining methods. In: Collee JG, Fraser AG, Marmion BP, Simmons A, editor. Mackie and McCartney Practical Medical Microbiology. 14th edition New York: Churchill Livingstone 1996; 796-800.

17. Collee JG, Miles RS, Watt B. Tests identification of Bacteria. In: Collee JG, Fraser AG, Marmion BP, Simmons A, editor. Mackie and McCartney Practical
Medical Microbiology. 14th edition New York: Churchill Livingstone 1996; 113-130.

18. Antimicrobial Susceptibility Testing. Winn Jr WC, Allen SD, Janda WM, Koneman EW, Procop GW, Schreckenberger PC, editor. Koenman's color Atlas and Text book of Diagnostic Microbiology, 6th edition. Philedelphia: Lippincott Williams and Wilkins; 2006; 946-1014.

19. Donlan RM. Biofilms and deviceassociated infections. Emerg Infect Dis 2001 March-April; 7(2):277.

20. Trautner B, Darouche R. Role of biofilm in catheter-associated urinary tract infections. Am J Infect Control 2004; 32(3): 177-83.

21. Chaudhari R, Deshpande A, Angadi S A, Koppikar G V. A preliminary study of Catheter Associated Bacteriuria. Bombay hospital journal 2015; 1-5.

22. Poudel C M, Baniya G, Pokhrel B M. Indwelling catheter associated urinary tract infection. Journal of institute of Medicine, Dec. 2008. vol.30:3; 2-7.

23. Chatterjee S, Maiti PK, Dey R, Kundu AK, Dey AK. Biofilm on indwelling urological devices: Microbes and Antimicrobial management prospect. Annals of Medical and Health Sciences Research. Jan-Feb 2014: vol 4; issue 1; 100-104.

24. Dimri S, Sharma H, Datta S K, Gupta D. A study of urinary tract infections in patients with catheter in tertiary care hospital in Western Uttar Pradesh. Int Jor of Contemporary Surgery. July-Dec. 2013. vol. 1; issue 2; 83-86.

25. Bhatia N, Daga M K, Garg S, Prakash S $\mathrm{K}$. Urinary catheterization in medical wards. Journal of global infectious diseases, 2010. vol.2; issue 2; 83-90.

26. Prajapati D K, Gupta A, Prajapati R, Gupta A. Epidemiological study of catheter associated urinary tract 
infection in surgical patients in Gajra Raja Medical College, Gwalior. IOSR Journal of Dental and Medical Sciences. September 2015. vol. 14; Issue 9; 77 81.

27. Roel T, Sahoo B, Sulochana K, Deban L, Kamli Y, Aribam V D. Susceptibility pattern of bacterial isolates from catheterized patients in a referral hospital.

28. Raksha R, Srinivasa H, Macaden RS. Occurrence and characterization of uropathogenic Escherichia coli in urinary tract infections. Indian $\mathrm{J}$ Med Microbiol 2003; vol.21:102-7.

29. Kausar Y, Chunchanur SK, Nadagir SD, Halesh LH, Chandrasekhar MR. Virulence factors, serotypes and antimicrobial susceptibility pattern of Escherichia coli in urinary tract infections. J Med Sci 2009; vol.2:47-51.

30. Manish N, Tankhiwale N S. Study of microbial flora in patients with indwelling catheter. Int. J. Current Research and Review. June 2013. vol. 5 ; issue $12 ; 57-60$.

\section{How to cite this article:}

Deepa Bhani, Rekha Bachhiwal, Rajni Sharma and Rakesh Kumar Maheshwari. 2017. Microbial Profile and Antimicrobial Susceptibility Pattern of Uropathogens Isolated From Catheter Associated Urinary Tract Infection (CAUTI). Int.J.Curr.Microbiol.App.Sci. 6(8): 2446-2453. doi: https://doi.org/10.20546/ijcmas.2017.608.289 